\title{
Color-Coded US Politics: Media Frames Found in US Newspaper Articles from 2004 to 2012
}

\author{
Benjamin Gross ${ }^{1}$, Emily LoBello ${ }^{1}$ \\ ${ }^{1}$ School of Arts \& Sciences, Saint Bonaventure University, Saint Bonaventure, NY, USA \\ Correspondence: Benjamin Gross, School of Arts \& Sciences, Saint Bonaventure University, Saint Bonaventure, NY, \\ USA, 14778
}

Received: June 15, 2015 Accepted: September 10, 2015 Online Published: September 30, 2015

doi:10.11114/smc.v3i2.1048 URL: http://dx.doi.org/10.11114/smc.v3i2.1048

\begin{abstract}
During the 2000 US Presidential election, the terms "blue states" and "red states" emerged as a way to describe the political landscape of the United States. While these terms have become common heuristics used to organize how people think about politics, there is no singular agreed upon interpretation of what these terms tell us about America politics. This paper reviews the literature on framing and then discusses the identification of six media frames constructed around these terms between 2004 and 2012. Then, using a sample of 607 US newspaper articles, quantitative analysis indicates that the prevalence of particular frames changes during Presidential election years and by types of author. Overall, we find that frames vary in frequency depending on when the publication date and type of author, while also exploring how writers have used increasingly applied these terms towards seemingly apolitical realms of everyday life.
\end{abstract}

Keywords: media frames, American politics, political polarization, political media, mass media

\section{Introduction}

The red and blue state color coding scheme began in 1976, where 'blue state' referred to states that supported the Republican Party candidate - Gerald Ford - and 'red state' denoted those that voted for Democratic Party candidate Jimmy Carter (Elving, 2014). Between 1980 and 2000, color coding schemes varied arbitrarily by TV network from one election to the next (Zeller, 2004; Elving, 2014). But it was the highly contested US Presidential election between George W. Bush and Al Gore in 2000 that turned the television network color coding schemes of red and blue states into a shorthand system for describing political differences throughout the US (Richardson, 2008). Since 2000, the networks have maintained a consistent color coding scheme of blue to represent states which have selected Democratic candidates and red to identify states supporting Republican candidates.

These terms continue to be used today by the networks (and others) to describe political attitudes at both individual and geographic levels. Red state and blue state have become a common part of the American lexicon, used when people of all backgrounds apply these terms to reflect their perceptions about the political values and beliefs of other Americans. However, the meaning behind these terms still remains fairly ambiguous. Sometimes they are applied to describe geographic regions, and at other times attached to individuals (often as caricatures or stereotypes of the political group they support). Likewise, red and blue can refer to political candidates and specific policies, or generically as cultural shorthand for lifestyle behaviors not commonly associated with politics. Further exacerbating the problem is that usage of these terms comes from a wide array of authors who often use these terms differently based on their own understanding of US politics and American culture. This then embeds and applies a package of assumptions into the terminology across a spectrum of social contexts.

While the objective of this article is not to provide empirical evidence of whether Americans are more or less politically divided than in the past, a brief review of the political polarization literature will provide some context for why different "claims-makers" (Best, 2013) in the news media construct various depictions of America when referring to red states and blue states. What we find is that the usage of these terms has been far from multivalent. Instead, various packages of meanings, interpretations, and writer assumptions, referred to as "media frames" (Gamson \& Modigliani, 1989; Kuypers, 2006), have co-existed simultaneously in US newspapers. We also find that the popularity of frames is significantly impacted by type of author and the date of publication, reflective of the various claimsmakers that 
contribute in the public sphere. In addition, there has been an expansion of red and blue state language being applied to non-political activities, which could potentially be having the net effect of increasingly politicizing daily life among the American public.

\section{Material Studied}

\subsection{What are Media Frames?}

In his classic book "Frame Analysis", Erving Goffman (1974) discussed how the minds of human beings rely on frameworks in order to understand and interpret the social world. Goffman thought of a frame mainly in cognitive terms, viewing it as a set of concepts and theoretical perspectives which help people organize experiences. The concept of a frame is based on the idea of a picture: a frame structures and organizes the pieces of a photo together into a meaningful coherence, helping a person understand what he or she is experiencing. Frames help us see and understand the picture; they channel our attention, impact our perceptions, and can lead us to ignore information which falls to the outside of it.

Media frames have been used widely in media studies over the last forty years as a way of explaining how the public perceives and interprets media content. Authors like George Lakoff (2004) have discussed how frames are analogous to cognitive maps that impact how viewers believe they should recognize, understand and process information. While the recipients of mediated messages have the ability to reject or transform the frameworks imposed on them in a competing marketplace of ideas (Thompson, 1995), they often do not, making frameworks a strong tactic of persuasion (Lakoff, 2006; Luntz, 2007). Frameworks have been shown to impact how people make decisions, alter beliefs, and change intended courses of actions in a variety of social contexts (Tversky \& Kahneman, 1981; Iyengar, 1991; Gilens, 2000; Luntz, 2007; Fairhurst \& Sarr, 2007; Fairhurst, 2010; Kendall, 2011).

Frames operate in four key ways: they define problems, diagnose causes, make moral judgments, and suggest remedies. They are often found within a narrative account of an issue or event, and are generally the central organizing idea of a story (Kuypers, 2006). Frameworks are important for understanding how Americans understand and interpret socio-political issues. People have a tendency to accept only the facts which fit within the framework of the discussion, as frames are pervasive and critical to political discussion and thought which structure our ideas and reasoning (Gitlin, 1980; Lakoff, 2006; Luntz, 2007). As a result, frames are viewed as critical for the structure of political debate. Those who are able to create and maintain frames built around their own assumptions and viewpoints will be able to control political discourse and the ways in which the general public thinks about social issues (Lakoff, 2004; Luntz, 2007). Previous research on media frames has identified how frames impact public understanding of a wide array of social and political issues, such as labor disputes (Martin, 2003), nuclear energy policy (Gamson \& Modigliani, 1989), war in the Middle East (Kuypers, 2006; Butler, 2009), affirmative action (Gamson \& Modigilani, 1987), and beliefs regarding race and poverty (Iyengar, 1991; Emtman \& Rojecki, 2000; Gilens, 2000; Kendall, 2011).

\subsection{Has the United States Become More Polarized?}

While there are some authors who challenge the validity of the red and blue state terminology (McCormick, 2014; Gelman, 2008; Fiorina, Abrams, \& Pope, 2006; Webster, 2007; Gronbeck \& Wiese, 2005; Glaeser \& Ward, 2006; Levendusky \& Pope, 2011; Blakenau, Snowden, \& Langan, 2008; Geiguen \& Webber, 2014), there are others who understand red and blue states as an accurate representation of deep social, cultural and economic differences existing between people in the United States. The colors are often used as shorthand expression of deep divisions in political beliefs and values that are based on significant demographic differences in educational attainment, urbanization, and religiosity found within the nation. Researchers have identified a rise of political polarization in the US as being connected to a variety of socio-cultural practices such as religiosity (Silk \& Walsh, 2008; Gelman, 2008; Abromowitz \& Saunders, 2008), family law and socialization (Cahn \& Carbone, 2011; Monson \& Mertens, 2011), household income (Gelman, 2008), abortion, gun ownership (Greenberg, 2004; Abramowitz \& Saunders, 2005), environmentalism (Crouch \& Abbot, 2009; Sautter \& Sautter, 2010) and educational policy (Crouch \& Abbot, 2009; Wiley \& Siperstein, 2011). Additionally, political beliefs become more ideological on a wide array of social and cultural issues (Greenberg, 2004; Abramowitz \& Saunders, 2005; Bishop, 2008; Gelman, 2008).

Many of these authors would argue that the result has been a rise in polarized political attitudes among the US public, where party identification and loyalty have increased, and also where cultural issues taken precedence over economic ones (Frank, 2004; Baum 2011; Highton, 2012). This is consistent with what Richard Inglehart (1977) had previously referred to as "post-materialist" politics, where a large percentage of Americans allow their cultural and religious values to trump their own economic self-interests when they vote (Frank, 2004). Within this context, the red and blue color-codified labels become an emblematic expression of a 'culture war' taking place in the US, and are meant to signify a deep cultural divide that can be seen within the realms of everyday practices.

The use of red and blue state language to illustrate a post-materialist expression of values can also expand to a larger 
constellation of social activities that have previously been characterized as non-political in nature. Political discourse transitions from concrete policy considerations to in-group and out-group stereotyping (such as the "latte liberal") that connect voter identity to lifestyle practices, often being expressed in derisive language and rhetoric (Frank, 2004). Several academic writers have recently noted that Americans are increasingly self-selecting themselves into personalized communities based on shared political identity and lifestyle at a higher degree than ever before. Acceptance into these communities are primarily based on voluntary and contingent membership with like-minded others (Florida, 2002; Frank, 2004; Sunstein, 2007; Bishop, 2008; Florida, 2008; Manjoo, 2008; Sunstein, 2009), where it is feared that increasing levels of political polarization in the US through continual ideological reinforcement and ideology-based self-segregation takes place.

\subsection{Frame Analysis of "Red States" and "Blue States"}

Our current research is an extension of previous frame analysis regarding the usage of 'red states' and 'blue states' in US newspapers conducted between the years of $2004-2007$, where six identifiable frameworks were found to exist simultaneously with one another in the public sphere. These frames were labeled as "Call for Unity", "Culture War", "How to Win", "Partisan", "Lifestyle Stereotype", and "Purple State" (Gross, 2013). Some frames, such as "Partisan" and "Culture War", described the political landscape as a representation of bitter political differences between Democrats and Republicans, where deep divisions were understood to be the product of important socio-demographic traits. This was purported to lead people to major differences that could be seen in cultural values, policy preferences, and political party affiliation. Other writers, often using the "How to Win" and "Lifestyle Stereotype" frames, assumed that there were two Americas, where wise citizens and savvy politicians should recognize this new political reality. Writers often identified social markers and political policies that represented deep divides between red and blue America. Nevertheless, there were some who rejected the red and blue state paradigm, such as the "Call for Unity" and "Purple State" frames. Readers were asked to ignore claims of America as a bitterly divided nation, and to question the validity of states being fully conservative or liberal.

In sum, all viewpoints were found to simultaneously exist in US newspapers during this time period, with none receiving a disproportionate amount of usage. This finding was consistent with the seminal research conducted by Gamson and Modigliani (1989), which found that news media discourse regarding nuclear power, was multivalent, reflecting a wide array of assumptions, facts, and viewpoints that co-existed over multi-year time period.

Our aims are to identify if the earlier framing of the terms 'blue state' and 'red state' is still applicable, while also finding if unique time periods or specific authors effects the frequency of when these frameworks are found in US newspapers. To answer these questions, we will use the coding system and expand upon the data set of newspaper articles used in earlier research (Gross, 2013), to encompass an eight year time period from 2004 to 2012. Our research questions include the following:

1. Are the frameworks found in earlier research still applicable to today's newspaper coverage, or have different frameworks emerged?

2. Are there any notable differences within the existing frameworks that can be identified?

3. Do frame usage patterns differ during presidential election years? If so, how?

4. Do editorialists and journalists differ in which frameworks they utilize to describe the American political landscape, and how so?

\section{Methodology}

Using a Lexis-Nexis search of US-newspapers, 270 articles using the terms "red state" and "blue state" were identified between 2008 and 2012. All of these articles were subjected to the same assortment of content analysis coding techniques previously conducted in the earlier research on this topic (Gross, 2013), where six unique media frames had been identified. Our inter-coder reliability score $=.80$, which is considered acceptable. Next, these 270 coded articles were merged with the 337 earlier articles (from 2004 to 2007) that had been subjected to precisely the same manifest coding scheme (Gross, 2013). This gave us a total of 607 news stories that spanned the years 2004 to 2012.

Our analysis utilized latent qualitative analysis in order to deconstruct meaning and explore any assumptions being made by the writers. In addition, quantitative techniques were used to uncover any statistically significant differences in frame usage patterns over time, and by author, using SPSS software. The complete list of the specific questions and categories that were used in the article coding process can be found in appendix A.

\section{Results}

Overall, we found that the frameworks found in earlier research are still highly applicable to current newspaper coverage. When reading the articles, we found that all of the main themes and ideas related to the six frames discussed 
earlier were easy to observe from 2008 to 2012 and that no new frameworks were identifiable. During this time period, the most commonly found frame in our sample was the Partisan frame (153 times, 25.2 percent) with Purple State found least often (70 times, 11.5 percent). The data also revealed that that is a small but statistically significant relationship between year of the article and the frame of the news article (Cramer's $\left.\mathrm{V}=.150^{* *}, \mathrm{p}=.004\right)$. While it is fair to say that a high amount of heterogeneity exists in news coverage, some frameworks do appear slightly more often than others.

To investigate these changes further, we constructed table one to see if there is a noticeable alteration in patterns between the two time periods of 2004-2007 and 2008-2012. Here, it can be seen that frameworks which assume substantial existing differences in values among the public (How to Win and Lifestyle Stereotype) have become more popular since 2008. We interpret this finding as evidence that writers increasingly perceive that there are large divisions among the US public, whether or not this assumption is actually true. Likewise, the frameworks which discard or downplay political differences (Call for Unity and Purple State) are found the least often.

Table 1. Framework Usage Before and After 2008

\begin{tabular}{lccc}
\hline Framework & $\begin{array}{c}\text { Articles written } \\
\text { from 2004-2007 }\end{array}$ & $\begin{array}{c}\text { Articles written } \\
\text { from 2008-2012 }\end{array}$ & $\begin{array}{l}\text { Total Number } \\
\text { of Articles }\end{array}$ \\
\hline Call for Unity & $39(11.6 \%)$ & $34(12.6 \%)$ & $73(12.0 \%)$ \\
How to Win & $46(13.6 \%)$ & $60(22.2 \%)$ & $106(17.5 \%)$ \\
Culture War & $58(17.2 \%)$ & $49(18.1 \%)$ & $107(17.6 \%)$ \\
Purple State & $42(12.5 \%)$ & $28(10.3 \%)$ & $70(11.5 \%)$ \\
Lifestyle Stereotype & $45(13.3 \%)$ & $53(19.6 \%)$ & $98(16.1 \%)$ \\
Partisan & $107(31.8 \%)$ & $46(17.0 \%)$ & $153(25.2 \%)$ \\
\hline Total & $\mathbf{3 3 7}(\mathbf{5 5 . 5 \% )}$ & $\mathbf{2 7 0}(\mathbf{4 4 . 5 \% )}$ & $\mathbf{6 0 7}(\mathbf{1 0 0 \%})$ \\
\hline
\end{tabular}

Since the largest gains seen with the How to Win and Lifestyle Stereotype frames, we set out to further clarify and illustrate the ideas within these two frameworks by highlighting examples of their usage since 2008. In regards to the former, the How to Win frame is becoming the most commonly used framework as time passes. This rise in frame frequency represents the conclusion of many writers (primarily journalists) that savvy politicians should be using these sociological factoids for their own utilitarian purposes. In our sample, half of the How to Win articles focused exclusively on a "battleground" state, with virtually all of them also referring to a recent polling statistic. These articles define the problem in terms of numbers rather than ideas, on electability rather than ideology, and are spaces where pundits suggest that policy and campaign funds can be used as instruments for altering the current political scoreboard.

When discussing politics, candidates were often portrayed as pandering, perhaps reasonably so, disproportionately to battleground states. This is described by political strategist Ari Fleischer in a USA today article written by Richard Wolf (2011, Pg. 4A), where the logic of Presidential campaign strategy is explained as impacting Barack Obama's political actions.

"Travel these days largely is to 'purple' states. It's the reality of presidential Competition...I don't fault the president for visiting states that will make the most difference in his bid for re-election The states that were closest

in the 2008 election -- Missouri, North Carolina, Indiana and Florida -- have received at least five Obama each. His first trip as president was to Indiana, which he won by less than 1\%. Before that week was out, he also hit Florida and Virginia, both crucial swing states."

This article also indicated that political strategists from both parties understand the geographical component of American politics well, carefully planning their rhetoric accordingly. The following was added by Democratic Party strategist Josh Earnest, who said that:

"Policy, geography and logistics play greater roles in choosing sites. We look for venues where he can emphasize or reinforce a larger message...I don't think it's a surprise that the president travels more frequently to the States that have more people in them."

While both parties were viewed as being influenced by the electoral map during an election year, other writers noted how President Obama specifically crafted policy messages to the public based on the politics of the geographic region even in non-election years. For example, when discussing how Barack Obama should discuss Obamacare with the public, political pundit Lanny Davis (2012, Pg. 7A) suggested that:

"Obama has to start talking about health care reform repeatedly as a centrist public-private must command the message heights that the bully pulpit of the presidency uniquely provides him."

Taken together, the problems of American politics are defined within this framework more as a red team and blue team competition rather than about the authentic stances and best intentions of politicians. The behavior of political actors can be read as manipulative, offering the public contrived rhetorical messages, and who use red and blue state labels to 
help party experts dissect the public in order to advance themselves. The packaging of politics in this fashion may induce the readers of these texts to grow cynical about parties, politicians, and even the facts being reported about the political issues themselves. Perhaps more troublesome is the increasingly high frequency that these articles are found, as the How to Win frame comprised nearly 1 in 4 US newspaper articles, according to our sample.

Our research also showed an increased number of highly specific differences between liberals and conservatives that were frequently noted within the Lifestyle Stereotype frame since 2008. We found that discourse invoking red and blue state terminology, particularly in the hands of those who are not political experts, has less to do with specific policies or politicians than about differences that are visible to all in daily lifestyle patterns among the populous. The red/blue paradigm is often applied to topics that seem apolitical on the surface, and may be effectively politicizing more of everyday life, whether intended or not by the authors. As an example of this expansion, the following newspaper article topics found a way to reference political partisanship to the red and blue color-coding political paradigm:

$\checkmark$ One's food and drink preferences (Funt, 2008; Steuver, 2010; Bruni, 2011)

$\checkmark \quad$ The likelihood of purchasing an imported car (Ehart, 2009)

$\checkmark$ Taste in music and television shows (Stewart, 2008; Cavna, 2009; Dunham, 2009; Malitz, 2009; Steuver, 2011; Leitko, 2012)

$\checkmark$ Voting in the Academy Awards, the Grammies, and the Rock n' Roll Hall of Fame (Harris, 2008; De Moraes, 2009; Stevens, 2011)

$\checkmark \quad$ The selection of baby names (D'Arcy, 2012)

$\checkmark$ Student choice of a college major (Brooks, 2012)

$\checkmark$ Preferences for different sports, or in fandom for various sports teams (Davis, 2008; Hruby, 2010; Maese, 2012)

One of the most interesting changes in the packaging of framed meanings over the last five years has been the expansion of political language and rhetoric into new realms, which we expect has made political differences more salient to audiences. Many of these articles took non-political issues and made them appear to be political. Maybe the most illustrative and entertaining example of this came from Aaron Leitko (2012, Page B03), when he discusses a character from the show "The Walking Dead" in the Washington Post, saying:

"Daryl Dixon is a redneck jedi. Dixon acts decisively, setting aside moral hand-wringing to kick butt. While "The Walking Dead's" sophisticates debate the ethics of killing the undead, this lovable rube rolls up his sleeves to get the necessary zombie-butchering done."

While this quote (and several others) could be read as humorous and arguably not intended to be serious political discourse, it is striking to see how many times the red/blue terms are used to illustrate conflicts, rivalries, and major social differences that are assumed to be self-evident. The presentation of cultural and political bifurcation as absolute was present in many frameworks, but the Lifestyle Stereotype often extend political battles to new arenas.

As an example of politicization, an article written by Hampton Stevens (2011, Pg. 10) directly questioned whether politics plays a role in the voting for the Rock n' Roll hall of fame, suggesting that favoritism is in play when he claiming the following:

"But that big tent gets tiny when it comes to music that mainstream Red America loves - especially music that appeals to straight, white, working-class men. Journey isn't in the hall. Neither is Jethro Tull, Boston, Bon Jovi, the Cars, ELO, the Steve Miller Band or Stevie Ray Vaughn. Nor is Kansas. Or Styx. Or Ted Nugent. Get the picture?"

Reality television shows were another space where politics in the form of red and blue state stereotyping occurred, where the jokes and show content illustrate differences. The following quote by Hank Steuver (2011, Pg. T08) reviews the show "Hillbilly Handfishin" through the prism of political rhetoric:

"This is the recurring idea of "Hillbilly Handfishin'": People from cities sure don't know much about anything useful. In the reverse (if, say, the show followed Skipper and Jackson to Manhattan to negotiate the subsidiary rights of their TV show over lunch with network executives at the Four Seasons), this sort of cheap-shot cultural crossover would seem offensive and mean. But of course, red-state humor about urban effetes is always allowable; in fact, it is viewed as a social corrective to some imagined blue-state tyranny."

Even celebrity chefs were not beyond the scope of politicization when editorialist writer Frank Bruni (2011, Pg. 27) discussed Paula Deen and Anthony Bourdain, noting that:

"Her retort exposes class tensions in the food world that sadly mirror those in society at large. You can almost imagine Anthony Bourdain and Paula Deen as political candidates, a blue-state paternalist squaring off against a red-state populist over correct living versus liberty in all its artery-clogging, self-destructive glory." 
Using the definition of a framework mentioned earlier by Kuypers (2006), the problem is defined around difference in values, which are reflected in everyday practices, perhaps even operating at subconscious levels. This framework largely assumes that the vague caricatures such as the ones described by Tom Frank (2004) are real, accurate, and are never disputed by the writers. Additionally, these articles rarely, if ever, mention any specific politicians or policies. They also do not attempt to connect red and blue stereotypes to any particular event, or question how these stereotypes were constructed, but simply that they exist and are present almost everywhere in our culture. We view these articles as problematic in the subtle, innocuous ways that they acknowledge strong difference and unquestionably validate the labels attached to red and blue America. While an understanding of how these frames persuade people or how effective they are at shaping political attitudes lays beyond the scope of this article, future research of these frames may provide beneficial to gaining a better understanding of political polarization in the US.

Next, we set out to uncover if there were different frameworks usage patterns during presidential election years, and identify how do they differed. In table two, it can be seen that there are small but significant differences in frame frequency when comparing US Presidential election years $(2004,2008$, and 2012) to the rest of the data set (Chi-Square $=12.114, \mathrm{p}=.033$; Cramer's V $\left.=.141^{*}\right)$. It can be seen that in non-election years, the Lifestyle Stereotype frame is more common, comprising 20 percent of newspaper articles, but declining to roughly 13 percent at other times. During Presidential election years, all other types of stories increase, especially the How to Win framework. Writers often spend election years, perhaps unsurprisingly, trying to predict results via current polling numbers. In contrast, non-Presidential election years involve a more qualitative and descriptive cultural account 'red' or 'blue', being used as a linguistic shorthand for how to define our differences in values and categorize the US populous.

Table 2. Framework Usage and Presidential Election Coverage

\begin{tabular}{lccc}
\hline Framework & Election Year & Not Election Year & \multicolumn{1}{l}{ Total } \\
\hline Call for Unity & $48(13.8 \%)$ & $25(9.6 \%)$ & $73(12.0 \%)$ \\
How to Win & $69(19.9 \%)$ & $37(14.2 \%)$ & $106(17.5 \%)$ \\
Culture War & $65(18.7 \%)$ & $42(16.2 \%)$ & $107(17.6 \%)$ \\
Purple State & $41(11.8 \%)$ & $29(11.2 \%)$ & $70(11.5 \%)$ \\
Lifestyle Stereotype & $46(13.3 \%)$ & $52(20.0 \%)$ & $98(16.1 \%)$ \\
Partisan & $78(22.5 \%)$ & $75(28.8 \%)$ & $153(25.2 \%)$ \\
\hline Total & $\mathbf{3 4 7 ( 5 7 . 2 \% )}$ & $\mathbf{2 6 0 ( 4 2 . 8 \% )}$ & $\mathbf{6 0 7 ( \mathbf { 1 0 0 \% } )}$ \\
\hline
\end{tabular}

Our fourth research question examined whether editorialists and journalists differed in which frameworks they utilize to describe the American political landscape, and to also determine how they differ. What we found is that editorialists, which were primarily either well-known political pundits or members of the general public, differed in how they used red and blue to construct narratives of political sentiment.

Table three compares the framework frequency usage between journalists and editorial writers between the years 2004 to 2012. The data indicates that there is a moderately strong and statistically significant relationship between editorials and framework usage (Chi-Square $=36.03, \mathrm{p}=.000$, Cramer's $\mathrm{V}=.244^{* *}$ ). More specifically, editorialists were more likely to use the Partisan framework (37.7 versus 19.5 percent), as editorialist contributions often were venomous critiques of the President and his administration. Nevertheless, editorials were also more likely to challenge the assumption of a divided America as well, since these writers were slightly more likely to construct Call for Unity (13.6 versus 11.3 percent) and Purple State (13.6 versus 10.6 percent) narratives.

When editorialists use red and blue terminology, the writers are generally either angry about existing political differences, or else they are claiming that the divide is exaggerated. Political pundit editorialists often used these terms to attack opponents, and illustrate specific ways in which the President, in particular, has an opinion that is at odds with the American public. At the same time, however, other editorialists questioned whether America was really divided at all, and asked readers to questions the validity of red and blue state terminology.

Table 3. Framework usage between Editorialists \& Other Writers

\begin{tabular}{lcrr}
\hline Framework & Editorial & Not Editorial & Total \\
\hline Call for Unity & $26(13.6 \%)$ & $47(11.3 \%)$ & $73(12.0 \%)$ \\
How to Win & $17(8.9 \%)$ & $89(21.4 \%)$ & $106(17.5 \%)$ \\
Culture War & $29(15.2 \%)$ & $78(18.8 \%)$ & $107(17.6 \%)$ \\
Purple State & $26(13.6 \%)$ & $44(10.6 \%)$ & $70(11.5 \%)$ \\
Lifestyle Stereotype & $21(11.0 \%)$ & $77(18.5 \%)$ & $98(16.1 \%)$ \\
Partisan & $72(37.7 \%)$ & $81(19.5 \%)$ & $153(25.2 \%)$ \\
\hline Total & $\mathbf{1 9 1 ( 3 1 . 4 \% )}$ & $\mathbf{4 1 6}(\mathbf{6 8 . 6 \%})$ & $\mathbf{6 0 7 ( 1 0 0 \% )}$ \\
\hline
\end{tabular}


On the other hand, journalists tended to use red and blue as team colors in a political contest, being much more likely to engage in 'horserace' coverage of politics with the How to Win Frame (21.4 versus 8.9 percent), and also more likely to construct a Lifestyle Stereotype (18.5 versus 11 percent) and Culture War (18.8 versus 15.2 percent) depiction of the US populous. We found that political journalists are slightly, but statistically significantly, more likely to describe American politics in ways that assume the strong divisions are real, are evident in everyday practices, and that the validity of the color coded terms is challenged less often.

\section{Discussion}

Overall, the findings of our research can be summarized as follows: The media frames found in earlier research are still highly applicable to today's news coverage.

Six red and blue state frames simultaneously co-exist, and US newspapers mainly provide audiences with multivalent packages of meanings when using these terms. However, the prevalence of frames is impacted by Presidential elections. While the Partisan framework was most common from 2004 to 2007, The How to Win frame has been used with the highest frequency since then. This shift to How to Win frames suggests that red/blue usage is less about solutions to social problems and more about how politics is a game between two competing teams looking for successful point-gaining strategies. Further research may be able to identify whether audiences reading How to Win frames become more cynical of politicians, or create a sort of "fandom" of the red and blue "teams' that are depicted as two groups competing intensely against each other in perpetuity. There is also a higher amount of red and blue state terminology usage during Presidential election years. Between 2004 and 2012, 57.1\% of all the articles using these terms were found during the three Presidential election years (2004, 2008, and 2012). In non-election years, red and blue become more likely to be used to describe US culture and maintain Lifestyle Stereotypes of people whose living practices exhibit politicized values and behaviors. The Lifestyle Stereotype and How to Win frames have become more prevalent in recent years. Both of these article types assume that major political divisions exist in the US, and that only the foolish will ignore this political reality. Readers may increasingly be experiencing texts which politicize events, people, their own culture, while raising skepticism about politicians and parties. Future research may be able to decipher whether audiences consuming these messages develop more extreme political attitudes, more political apathy, or if the effects of these texts are largely benign. The majority of political writers at least perceive that there are large and meaningful differences among the US public. Frameworks that assume there are bitter political divisions in the US are more common than others. Over the last ten years, about 75 percent of the news articles we coded view political difference as factual and based on major differences in values and demographic backgrounds. The least prevalent frameworks in our sample were the two that openly question the validity of the red/blue state paradigm and claim that political differences are overstated. There is a significant difference between editorialists and journalists with regards to which media frames they construct. While no framework of red/blue state was dominant within American newspapers, it can be recognized that authors use these terms as a rhetorical political tool, using them in an attempt to influence the opinions of readers. The red and blue labels get applied to elections, policies, parties, geographical areas, cultural values, public sentiment, lifestyle practices, sports contests, and a wide variety of social activities that seemingly have little to do with politics. Because the usage is so varied, it is still nearly impossible to clearly and objectively define what "red state" or "blue state" really signifies. Instead, these labels are constructed and applied in a multitude of contexts by all types of authors, leaving these terms ambiguous and with a highly fluid meaning, even after decades of usage.

\section{Conclusion}

As discourse evolves regarding political polarization in the United States, terms such as red state and blue state will likely continue to surface and influence the opinions of newspaper readers. Overall, we find that frames vary in frequency depending on when the publication date and type of author, while also exploring how writers have used increasingly applied these terms towards seemingly apolitical realms of everyday life. While our analysis involves only a limited sample of all media texts written over this time period, the findings here can inform future researchers of how assumptions are embedded in political articles, as well as when and where they are likely to be found. We believe that this research can provide assistance to future researchers in order to help them more easily identify the framing of political discourse, and to compare those usage patterns to previous time periods. A limitation of this study is that the focus of the authors is placed entirely on the texts themselves, as measuring reader influence is beyond the scope of this project. Our hope is that future researchers will use experimental methods to discover whether readers encountering these frameworks show noticeable attitude change, verifying that these texts have important real-world ramifications. Additionally, future research could analyze other forms of print and visual media to understand if they exhibit the same frames, patterns of usage, and if the red and blue state terminology is found more or less often. Expanding into different dimensions of mass media content will give researchers a better grasp in regards to what everyday American commonly experience within the vast media landscape of today. 


\section{References}

Abramowitz, A. I., \& Saunders, K. L. (2005). Why Can’t We All Just Get Along? The Reality of a Polarized America. The Forum: A Journal of Applied Research in Contemporary Politics, 3(2), 1-24. http://dx.doi.org/10.2202/1540-8884.1076

Abramowitz, A. I., \& Saunders, K. L. (2008). Is Polarization a Myth? Journal of Politics, 70(2), 542-555. http://dx.doi.org/10.1017/S0022381608080493

Ansolabehere, S., Rodden, J., \& Snyder, J. M. (2006). Purple America. The Journal of Economic Perspectives, 20(2), 97-118. http://dx.doi.org/10.1257/jep.20.2.97

Baldassarri, D., \& Gelman, A. (2008). Partisans Without Constraint: Political Polarization and Trends in American Public Opinion. http://papers.ssrn.com/sol3/papers.cfm?abstract_id=1010098

Barrett, A. W., \& Barrington. L. B. (2005). Newspaper Photographs and Voter Evaluations of Political Candidates. Harvard International Journal of Press/Politics, 10(4), 98-113. http://dx.doi.org/10.1177/1081180X05281392

Baum, M. A. (2011). Red State, Blue State, Flu State: Media Self-Selection and Partisan Gaps in Swine Flu Vaccinations. Journal of Health Politics, Policy \& Law, 36(6), 1021-1059. http://dx.doi.org/10.1215/03616878-1460569

Best, J. (2013). Social Problems (2 ${ }^{\text {nd }}$ Ed.). New York, NY: WW Norton.

Bishop, B. (2008). The Big Sort. New York, NY: Houghton Mifflin Company.

Blankenau, J., Snowden, M., \& Langan, M. (2008). Understanding Environmentalism in a Red, Agricultural State: The Impact of Political Party Affiliation and Place of Residence. Sociological Spectrum, 28(1), 55-80. http://dx.doi.org/10.1080/02732170701675201

Brooks, D. (2012). The Service Patch. The New York Times, p. A31.

Bruni, F. (2011). Unsavory Culinary Elitism. The New York Times, p. A27.

Butler, J. (2009). Frames of War: When is Life Grievable? London: Verso Publishing.

Cahn, N., \& Carbone, J. (2011). Red Families v. Blue Families: Legal Polarization and the Creation of Culture. Oxford: Oxford University Press. http://dx.doi.org/10.1093/acprof:osobl/9780199836819.001.0001

Cavna, M. (2009). King of the Hill' Segues To the ABC of Animation. The Washington Post, p. C07.

Crouch, R. C., \& Abbot, D. S. (2009). Is Green Education Blue or Red? State-Level Environmental Education Program Development Through the Lens of Red- and Blue-State Politics. Journal of Environmental Education, 40(3), 52-62. http://dx.doi.org/10.3200/JOEE.40.3.52-62

D’Arcy, J. (2012). The most babylicious names. The Washington Post. p. T16.

Davis, L. (2008). Life with my 10-year-old son. The Washington Times, p. A04.

Davis, L. (2012). Why Dems should not gloat over health care ruling. USA Today, p. 7A.

De Moraes, L. (2009). Sealed With a Kris; In 'Idol' Upset, Allen's Newfound Stage Polish Beats Lambert's 'Guyliner'. The Washington Post, p. C01.

Dunham, N. (2009). A Natural Attraction. The Washington Post, p. WE08.

Ehart, W. (2009). Americans voting with their wheels, study finds; Ideology correlates to U.S.vs. import. The Washington Times, p. A01.

Elving, R. (2014). The Color of Politics: How did Red and Blue States Come to be? NPR Special Series. http://www.npr.org/2014/11/13/363762677/the-color-of-politics-how-did-red-and-blue-states-come-to-be?

Emtman, R. M., \& Rojecki, A. (2000). The Black Image in the White Mind: Media and Race in America. Chicago, IL: University of Chicago Press.

Entman, R. M. (1993). Framing: Toward Clarification of a Fractured Paradigm. Journal of Communication, 43(4), 51-58. http://dx.doi.org/10.1111/j.1460-2466.1993.tb01304.x

Fairhurst, G. T., \& Sarr, R. A. (2007). The Art of Framing: Managing the Language of Leadership. San Francisco, CA: Jossey-Bass Publishing.

Fairhurst, G. T. (2010). The Power of Framing: Creating the Language of Leadership ( $2^{\text {nd }}$ Edition). San Francisco, CA: Jossey-Bass Publishing. 
Fiorina, M. P., Abrams, S. J., \& Pope, J. C. (2006). Culture War? The Myth of a Polarized America. New York, NY: Pearson Education.

Florida, R. (2002). The Rise of the Creative Class: And How It's Transforming Work, Leisure, Community and Everyday Life. New York, NY: Basic Books.

Florida, R. (2008). Who's Your City? How the Creative Economy is Making Where You Live the Most Important Decision of Your Life. New York, NY: Basic Books.

Frank, T. (2004). What's the Matter with Kansas? New York, NY: Harry Holt \& Company.

Funt, P. (2008). Metrics That Point to C-L-I-N-T-O-N. The Washington Post. p. A17.

Gamson W. A., Croteau, D., Hoynes, W., \& Sasson, T. (1992). Media Images and the Social Construction of Reality. Annual Review of Sociology, 18(1), 373-393. http://dx.doi.org/10.1146/annurev.so.18.080192.002105

Gamson, W. A., \& Modigliani, A. (1987). The changing culture of Affirmative Action. Research in Political Sociology, (3), 137-177.

Gamson, W. A., \& Modigliani, A. (1989). Media Discourse and Public Opinion on Nuclear Power: A Constructionist Approach. American Journal of Sociology, 95(1), 1-37. http://dx.doi.org/10.1086/229213

Geiguen, S., \& Webber, D.J. (2014). Red States, blue states: How well do the recent national election labels capture state political and party differences? The Social Science Journal, 51(3), 386-397. http://dx.doi.org/10.1016/j.soscij.2014.04.006

Gelman, A. (2008). Red State, Blue State, Rich State, Poor State. Princeton, NJ: Princeton University Press.

Gilens, M. (2000). Why Americans Hate Welfare: Race, Media, and the Politics of Antipoverty Policy. Chicago, IL: University of Chicago Press.

Gitlin, T. (1980). The Whole World is Watching: Mass Media in the Making and Unmaking of the New Left. Berkeley, CA: University of California Press.

Glaeser, E. L., \& Ward, B. A. (2006). Myths and Realities of American Political Geography. Journal of Economic Perspectives, 20(2), 119-144. http://dx.doi.org/10.1257/jep.20.2.119

Goffman, E. (1974). Frame Analysis: An Essay on the Organization of Experience. Boston, MA: Northeastern University Press.

Greenberg, S. B. (2004). The Two Americas: Our Current Political Deadlock and How to Break It. New York, NY: Thomas Dunne Books.

Gronbeck, B. L., \& Wiese. D. R. (2005). The Repersonalization of Presidential Campaigning in 2004. American Behavioral Scientist, 49(4), 520-534. http://dx.doi.org/10.1177/0002764205279754

Gross, B. (2013). Color Coding Politics: Creating meaning around 'Red States' and 'Blue States' in US newspapers between 2003 and 2007. Sage Open Sociology Journal, 3(1), 1-10. http://dx.doi.org/10.1177/2158244013476053

Harris, M. (2008). Red vs. Blue in Hollywood, Too. The Washington Post, p. B01.

Highton, B. (2012). Sorting the American States into Red and Blue: Culture, Economics and the 2012 US Presidential Election in Historical Context. Forum, 10(4), 11-19.

Hruby, P. (2012). Football, like politics, a red-state/blue-state thing." The Washington Times, p. C10. Inglehart, R. (1977). The Silent Revolution: Changing Values and Political Styles Among Western Publics. Princeton, NJ: Princeton University Press.

Iyengar, S. (1991). Is Anyone Responsible? Chicago, IL: University of Chicago Press. http://dx.doi.org/10.7208/chicago/9780226388533.001.0001

Kendall, D. (2011). Framing Class: Media Representations of Wealth and Poverty in America (2 ${ }^{\text {nd }}$ Ed.). Lanham, MD: Rowman \& Littlefield Publishing.

Kuypers, J. A. (2006). Bush's War: Media Bias and Justifications for War in a Terrorist Age. Lanham, MD: Rowman \& Littlefield Publishers.

Lakoff, G. (2004). Don't Think of an Elephant: Know Your Values and Frame the Debate. White River Junction, VT: Chelsea Green Publishers.

Lakoff, G. (2006). Thinking Points. New York, NY: Farrar, Strauss, and Giroux.

Leitko, A. (2012). 'Redneck Jedi' to the rescue! The Washington Post, p. B03. 
Levendusky, M. S., \& Pope, J. C. (2011). Red States vs. Blue States: Going Beyond the Mean. Public Opinion Quarterly, 75(2), 227-248. http://dx.doi.org/10.1093/poq/nfr002

Luntz, F. (2007). Words That Work: It's Not What You Say, It's What People Hear. New York, NY: Hyperion Books. Maese, R. (2012). Blue \& Red State. The Washington Post, p. D01.

Malitz, D. (2009). A 'Fearless' Taylor Swift at Merriweather: Pop Without the Tart. The Washington Post, p. C02. Manjoo, F. (2008). True Enough: Learning to Live in a Post-Fact Society. Hoboken, NJ: John Wiley \& Sons, Inc. Martin. C. (2003). Framed! Labor and the Corporate Media. Ithaca, NY: ILR Press.

McCormick, J. (2014). Red vs. Blue? Pew Finds Eight Colors. Bloomberg News. http://go.bloomberg.com/political-capital/2014-06-26/red-vs-blue-pew-finds-eight-colors/

Monson, R. A., \& Mertens, J. (2011). All in the Family: Red States, Blue States, and Postmodern Family Patterns, 2000 and 2004. Sociological Quarterly, 52(2), 244-267. http://dx.doi.org/10.1111/j.1533-8525.2011.01203.x

Pierce, G. (2009). Inside Politics. The Washington Times. p. A6.

Richardson, V. (2008, November 5). Changes expected to red-blue electoral map; Democrats make inroads in Rocky Mountain West, South. The Washington Times, p. B03.

Sautter, J. A., \& Sautter, C. A. (2010). Price, Carbon, and Generation Profiles: How Partisan Differences Make the Future of Climate Change Uncertain”. Electricity Journal, 23(2), 71-75. http://dx.doi.org/10.1016/j.tej.2010.02.005

Silk, M., \& Walsh, A. (2008). One Nation, Divisible: How Regional Differences Shape American Politics. Lanham, MD: Rowman \& Littlefield.

Steuver, H. (2010). Food Revolution' regurgitates worst of reality pap. The Washington Post. p. C02.

Steuver, H. (2011, August 7). Yankees and noodlers, muckin' with classism. The Washington Post. p. T08.

Stevens, H. (2011, December 13). Where's the rock? Hall of fame snobs snub old standards of red states. The Washington Times, p. C10.

Stewart, A. (2008, November 4). Hinder: Rocking Like It's 1989. The Washington Post, p. C01.

Sunstein, C. R. (2007). Republic.com 2.0: Revenge of the Blogs. Princeton, NJ: Princeton University Press.

Sunstein, C. R. (2009). Going to Extremes: How Like Minds Unite and Divide. Oxford: Oxford University Press.

Thompson, J. B. (1995). Ideology and Modern Culture. Stanford, CA: Stanford University Press.

Tversky, A., \& Kahneman, D. (1981). The Framing of Decisions and the Psychology of Choice. Science, 211 (4481), 453-458. http://dx.doi.org/10.1126/science.7455683

Webster, G. (2007). The Electoral College Exacerbates the Red-Blue State Divide and Disenfranchises Ethnic Minorities. American Psychologist, 62(7), 701-703. http://dx.doi.org/10.1037/0003-066X.62.7.701b

Wiley, A., \& Siperstein, G. (2011). Seeing Red, Feeling Blue: The Impact of State Political Leaning on State Identification Rates for Emotional Disturbance. Behavioral Disorders, 36(3), 195-207.

Wolf, R. (2011). President's travels favor 2012 'swing' states. USA Today, p. 4A.

Zeller, T. (2004). Ideas and Trends; One State, Two State, Red State, Blue State. The New York Times, p. B9-10.

\section{$(\mathrm{cc}) \mathrm{EY}$}

This work is licensed under a Creative Commons Attribution 3.0 License. 